\title{
АНАЛИЗ КРЕДИТОСПОСОБНОСТИ ОРГАНИЗАЦИИ (НА ПРИМЕРЕ АО «ФРИДОМ ФИНАНС»)
}

\author{
Нургалиева А. М. к. э. н., $P h D$, доцент, \\ Жарылкасынова М. Ж. к. э. н., доцент, \\ Смагулова И. С. студенты 4-курса, \\ Каршалова Д. Т.
}

Республика Казахстан, город Алматы, Университет Нархоз

DOI: https://doi.org/10.31435/rsglobal_ijite/01062018/5661

\section{ARTICLE INFO}

Received 21 April 2018

Accepted 23 May 2018

Published 01 June 2018

\section{KEYWORDS}

creditworthiness,

stock market,

assets,

liabilities,

capital,

liquidity,

profitability,

creditworthiness indicators

\begin{abstract}
The most widespread method that directed to reduce credit risk is evaluation of creditworthiness of the organization. Therefore it is relevant to investigate thoroughly the method and procedure of analysis of creditworthiness. The complexness of evaluating creditworthiness leads to apply different methods. The world experiences shows it. There are variety of experience of different countries in evaluating liquidity and creditworthiness, and consequently the applied indicators are differ from each other. This paper considers method and procedure of evaluating creditworthiness based on example JSC 'Freedom Finance'. Thus, the research shows the role and meaning of the analysis of creditworthiness as a main criteria in developing effective credit relation between bank and client.
\end{abstract}

(C) 2018 The Authors.

Введение. Кризисные явления в экономике спровоцировали существенный рост неплатежеспособных предприятий.

Кредитоспособность предприятия показывает, насколько правильно компания управляет источниками финансирования, насколько рационально использует собственные и заемные средства, как строит взаимоотношения с внешней средой и партнерами. Таким образом, кредитоспособность в значительной мере определяет конкурентоспособность компании и потенциал ее дальнейшего развития. Поэтому вопросы применения современных методов оценки кредитоспособности компании, от качества которых зависит не только эффективность ее деятельности, но эффективность всей экономики, в сложившихся экономических условиях, являются приоритетными.

Исследование зарубежного опыта анализа кредитоспособности организации, представленным различными моделями (количественными и комплексного анализа, статистическими), может быть полезно для применения в отечественной практике.

Результаты исследования. Каждая кредитная сделка сопровождается определенными элементами риска: не погашения организациями займов в силу различных причин, не возврат начисленных вознаграждений, нарушение срока их выплаты.

Присутствие риска, его прямая связь от многих обстоятельств, от ситуаций и результатов работы организаций предрешают важность определения банком ряда систем показателей, основываясь которых можно оценить, может ли организации выполнить свои кредитные обязательства.

Кредитоспособность является качественным свойством организацией, способствующая к решению проблем о вероятности и условиях его выдачи кредитов, закрепленных в договоре банковского займа.

Оценка кредитоспособности нужно, во-первых, с необходимостью банка минимизировать риски и обеспечить стабильность его деятельности, во-вторых, анализировать его финансовое состояние для заключения соответствующих контрактов, а также выдачи займа.

Специалисты в основном понятие кредитоспособность организации трактуют, как их способность взять кредит и погашать его с начисленными вознаграждениями полностью в указанный срок, либо как способность вовремя и полностью возвращать займ с начисленными процентами. Кредитоспособность, считают М. И. Баканов, А. Д. Шеремет, это финансовое положение организации, позволяющее получить займ и вовремя его погашать. Оценивая 
кредитоспособность необходимо тщательно изучить кредитную историю, имидж, состояние и структуру имуществ, стабильность действий и другие данные ее деятельности» [1].

По мнению других авторов, кредитоспособность трактуется как способность в строго установленные периоды и в полной мере расплачиваться с соответствующими органами, может быть и банки и др. по предоставленным им займам». Е.С. Стоянова и др. говоря о высокой кредитоспособности, отмечают ее как достойное умение покрытия займов с вознаграждениями и прочими издержками» Г21.

Ж. Т. Жумаканов определяет сущность кредитоспособности предприятия как способность вовремя рассчитываться по срочным платежам за счет собственных средств Г31.

А. Султанова и А. Утегужина дают определение кредитоспособности как финансовохозяйственному состоянию организации, при котором наблюдается высокая эффективность применения заемных средств [4].

По мнению Г. Н. Джаксыбековой и А. М. Нургалиевой от эффективности и правильности существования кредитного механизма зависят не только получение в срок необходимых ресурсов отдельными организациями, но и темпы развития экономики страны в целом [5].

Анализ кредитоспособности организации, большинство ученых объективно считают, что основывается на систему установленных показателей (данных).

Подведя итог выше изложенного, отметим следующее. Так мы согласны с определением сущности «кредитоспособность», сформулированным О. И. Лаврушиным как наиболее полным, включающим способность возврата кредита заёмщиком [6]. Автором определена кредитоспособность заёмщика как способность проведения сделки с учетом принципов кредита (возвратность, срочность и платность). То есть кредитоспособность должна включать способность возврата процентов по взятым обязательствам, а не только возврата самого кредита. Но предлагаем включить в данное определение учет способности компании вернуть кредит в будущем, так как кредитоспособность в значительной мере определяет конкурентоспособность компании и потенциал ее дальнейшего развития. Если же рассматривать кредитоспособность с точки зрения самой компании, то данная характеристика точно указывает на эффективность деятельности компании, его конкурентоспособность и потенциал дальнейшего развития.

Анализ кредитоспособности проведен с использованием данных АО «Фридом Финанс». Акционерное общество «Фридом Финанс» было основано в 2006 году, осуществляет свою деятельность в соответствии с законодательством РК и является крупнейшим розничным брокером на отечественном фондовом рынке.

Компанией постоянно совершенствуются применяемые бизнес-процессы, формируется высококвалифицированная команда специалистов и осуществляется расширение деятельности (открытие филиалов). Данные процессы увеличивают доступность и открытость компании для клиентов.

Анализ основных рынков показал, что к основным потребителям компании являются физические лица. Деятельность компании как эмитента направлена на работу с розничными инвесторами на отечественном фондовом рынке, на увеличение ликвидности фондового рынка и расширения видов торговых ценных бумаг.

Для определения кредитоспособности рассмотрим подверженность АО «Фридом Финанс» отвечать по своим обязательствам, то есть проведем анализ финансового состояния компании (рисунок 1).

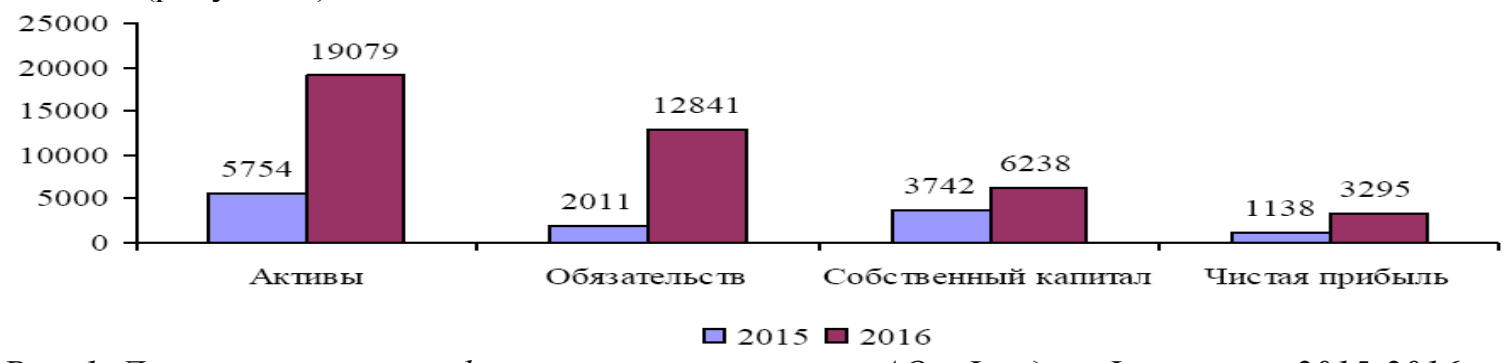

Рис. 1. Динамика основных финансовых показателей АО «Фридом Финанс» за 2015-2016 г2., млн. тенге

Примечание - составлено по данным финансовой отчетности АО «Фридом Финанс» [7]

Наблюдается рост по всем показателям, что указывает на рост эффективности деятельности компании. В 2015 году деятельность компании финансировалась в основном за счет собственного капитала (доля $65 \%$ в активах). В 2016 году доля собственных средств снизилась до 32,7 \%. Анализ имущественного положения компании представлен в таблице 1. 
Таблица 1. Динамика и структура активов АО «Фридом Финанс» за 2015-2016 гг.

\begin{tabular}{|c|c|c|c|c|c|c|}
\hline \multirow[b]{2}{*}{ Показатели } & \multicolumn{2}{|c|}{01.01 .2016} & \multicolumn{2}{|c|}{01.01 .2017} & \multicolumn{2}{|c|}{ Изменение } \\
\hline & $\begin{array}{l}\text { Сумма, } \\
\text { тыс. тенге }\end{array}$ & $\begin{array}{l}\text { Удельный } \\
\text { вес, \% }\end{array}$ & $\begin{array}{l}\text { Сумма, } \\
\text { тыс. тенге }\end{array}$ & $\begin{array}{l}\text { Удельный } \\
\text { вес, \% }\end{array}$ &,+- & $\%$ \\
\hline $\begin{array}{c}\text { Денежные средства и их } \\
\text { эквиваленты }\end{array}$ & 1094637 & 19,0 & 798190 & 4,2 & -296447 & $-27,1$ \\
\hline Средства в банках & 11164 & 0,2 & & 0,0 & -11164 & $-100,0$ \\
\hline $\begin{array}{c}\text { Финансовые активы по } \\
\text { справедливой стоимости через пр. } \\
\text { или убыток }\end{array}$ & 4336410 & 75,4 & 17742114 & 93,0 & 13405704 & 309,1 \\
\hline $\begin{array}{c}\text { Инвестиции, имеющиеся в } \\
\text { наличии для продажи }\end{array}$ & 459 & 0,0 & 459 & 0,0 & 0 & 0,0 \\
\hline $\begin{array}{c}\text { Основные средства и } \\
\text { нематериальные активы }\end{array}$ & 265263 & 4,6 & 247390 & 1,3 & -17873 & $-6,7$ \\
\hline Дебиторская задолженность & 17036 & 0,3 & 200288 & 1,0 & 183252 & 1075,7 \\
\hline Прочие активы & 29374 & 0,5 & 91154 & 0,5 & 61780 & 210,3 \\
\hline Итого активы & 5754343 & 100 & 19079595 & 100 & 13325252 & 231,6 \\
\hline
\end{tabular}

По состоянию на 31 декабря 2016 г. Активы компании АО «Фридом Финанс» увеличились на 231,6 \% по сравнению с началом года и составили 19079595 тыс. тенге. На рост активов повлияло значительное увеличение по статье «ценные бумаги, оцениваемые по справедливой стоимости, изменения которых отражаются в составе прибыли или убытка» на 309,1 \% - на 13405704 тыс. тенге в денежном выражении.

Также на изменение активов повлияло снижение денежных средств и эквивалентов денежных средств на 27,1 \% до 798190 тыс. тенге. Дебиторская задолженность увеличилась на $1075 \%$ и составила 200288 тыс. тенге на конец анализируемого периода. Доля дебиторской задолженности в активах компании составляет $1 \%$.

Итак, положительный рост активов произошел за счет увеличения портфеля ценных бумаг и связано с увеличением заемных средств (таблица 2)

Таблица 2. Динамика и структура обязательств АО «Фридом Финанс» за 2015 - 2016 гг.

\begin{tabular}{|c|c|c|c|c|c|c|}
\hline \multirow{2}{*}{ Показатели } & \multicolumn{2}{|c|}{01.01 .2016} & \multicolumn{2}{c|}{01.01 .2017} & \multicolumn{2}{c|}{ Изменение } \\
\cline { 2 - 8 } & $\begin{array}{c}\text { Сумма, } \\
\text { тыс. тенге }\end{array}$ & $\begin{array}{c}\text { Удельный } \\
\text { вес, \% }\end{array}$ & $\begin{array}{c}\text { Сумма, } \\
\text { тыс. тенге }\end{array}$ & $\begin{array}{c}\text { Удельный } \\
\text { вес, \% }\end{array}$ &,+- & $\%$ \\
\hline Выпущенные долговые цен. бумаги & 0 & 0,0 & 1505858 & 11,7 & 1505858 & - \\
\hline Обязательства по соглашениям Репо & 1968938 & 97,9 & 11300117 & 88,0 & 9331179 & 473,9 \\
\hline Кредиторская задолженность & 2807 & 0,1 & 3197 & 0,0 & 390 & 13,9 \\
\hline Прочие обязательства & 40134 & 2,0 & 32006 & 0,2 & -8128 & $-20,3$ \\
\hline Итого обязательств & 2011879 & 100 & 12841178 & 100 & 10829299 & 538,3 \\
\hline Примечание - составлено по данным финансовой отчетности АО «Фридом Финанс» [7] \\
\hline
\end{tabular}

Обязательства АО «Фридом Финанс» показали рост на 10829299 тыс. тенге, то есть в 6,3 раза. Существенный рост обязательств в 2016 году обусловлен увеличением краткосрочных заимствований в виде обязательств по соглашениям РЕПО на 9331179 тыс. тенге, а также выпуском долговых ценных бумаг на 1505858 тыс. тенге. Средства, полученные от выпуска долговых ценных бумаг, и заемные средства были направлены на увеличение собственного портфеля ценных бумаг (таблица 3):

Таблица 3. Динамика и структура капитала АО «Фридом Финанс» за 2015-2016 гг.

\begin{tabular}{|c|c|c|c|c|c|c|}
\hline \multirow{2}{*}{ Показатели } & \multicolumn{2}{|c|}{01.01 .2016} & \multicolumn{2}{c|}{01.01 .2017} & \multicolumn{2}{c|}{ Изменение } \\
\cline { 2 - 8 } & $\begin{array}{c}\text { Сумма, } \\
\text { тыс. тенге }\end{array}$ & $\begin{array}{c}\text { дельный } \\
\text { вес, \% }\end{array}$ & $\begin{array}{c}\text { Сумма, } \\
\text { тыс. тенге }\end{array}$ & $\begin{array}{c}\text { Удельный } \\
\text { вес, \% }\end{array}$ &,+- & 0 \\
\hline Акционерный капитал & 3068584 & 49,2 & 3068584 & 82,0 & 0 & 0,0 \\
\hline $\begin{array}{c}\text { Фонд переоценки инвестиций, } \\
\text { имеющихся для продажи }\end{array}$ & 162 & 0,0 & 162 & 0,0 & 0 & 0,0 \\
\hline Нераспределенная прибыль & 673118 & 50,8 & 3169671 & 18,0 & 2496553 & 370,9 \\
\hline Итого капитал & 3742464 & 100 & 6238417 & 100 & 2495953 & 66,7 \\
\hline Примечание - составлено по данным финансовой отчетности АО «Фридом Финанс» [7] \\
\hline
\end{tabular}


Размер собственного капитала по итогам 2016 года составил 6238417 тыс. тенге, увеличившись на 66,7\% по сравнению с предыдущим годом. Рост собственного капитала произошел за счет роста нераспределенной прибыли на 370,9 \%. Размер акционерного капитала не изменился.

Компания выполняет требования Национального Банка Республики Казахстан по достаточности собственного капитала (таблица 4).

Таблица 4. Сведения о выполнении пруденциальных нормативов на 01.01.2017 г.

\begin{tabular}{|c|c|c|c|}
\hline Показатели & 01.01 .2016 & 01.01 .2017 & Изм. + \\
\hline Ликвидные активы, тыс. тенге (ЛА) & 5531705 & 52935121 & 47403416 \\
\hline Обязательства, тыс. тенге (О) & 2398488 & 49182456 & 46783968 \\
\hline $\begin{array}{c}\text { Минимальный размер собственного капитала (МРСК) } 259 \\
200 \text { тыс. тенге (для УИП+БД1) }\end{array}$ & 259200 & 259200 & 0 \\
\hline $\begin{array}{c}\text { Коэффициент достаточности собственного капитала } \\
\text { К1=(ЛА-О)/МРСК, (К1>1) }\end{array}$ & 12,09 & 14,48 & 2,39 \\
\hline Выполнение нормативов К1 & Да & Да & \\
\hline
\end{tabular}

Коэффициент достаточности собственного капитала в 2016 году показал рост за счет увеличения ликвидных активов в 10 раз.

Динамика доходов представлена на рисунке 2.

AО «Фридом Финанс» в 2016 году была зафиксирована чистая прибыль в размере 3295953 тыс. тенге в сравнении с чистой прибылью в размере 1138185 тыс. тенге в 2015 году. К основным источникам доходов относятся комиссионные и финансовые доходы.

Одним из основных этапов изучения структуры капитала является анализ эффективности использования капитала предприятия.

Эффективность использования капитала характеризуется показателями рентабельности.

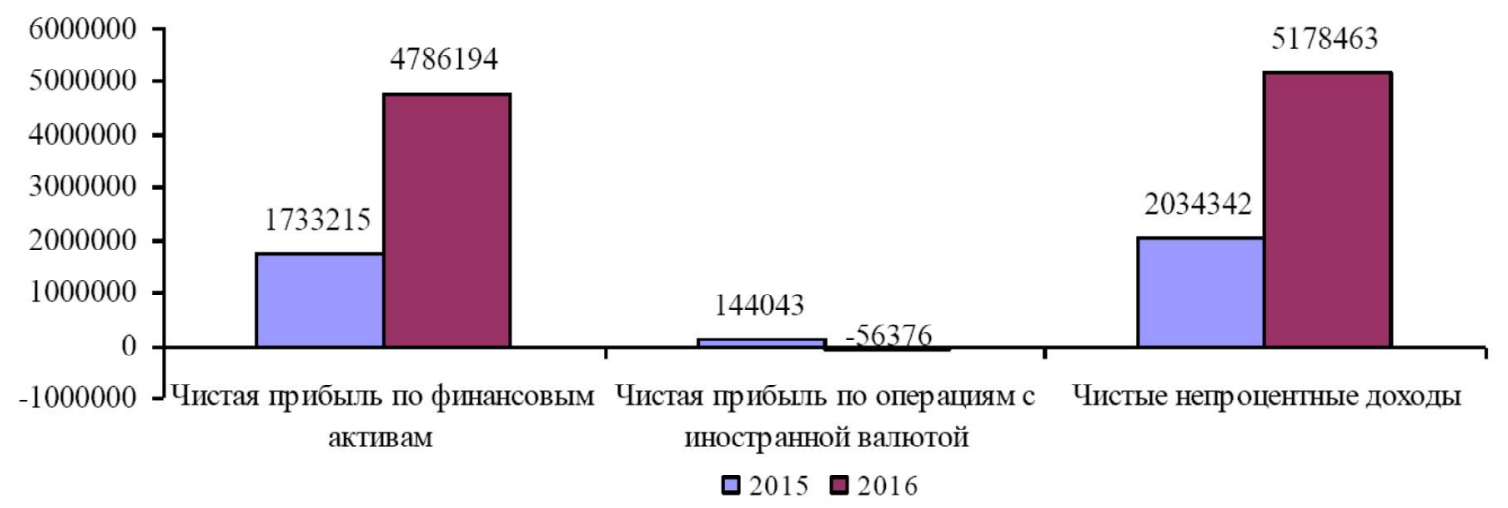

Рис. 2. Динамика доходов АО «Фридом Финанс», тыс. тенге

Примечание-составлено по данным финансовой отчетности АО «Фридом Финанс» [7]

Рентабельность представляет собой такое использование средств, при котором предприятие не только покрывает расходы, но и формирует прибыль. Анализ показателей рентабельности позволяет оценить текущую хозяйственную деятельность, выявить резервы и разработать меры по использованию данных резервов. За 2016 год наблюдается снижение рентабельности активов. Это значит, что прибыль, полученная от 1 тенге вложений в активы, то есть вложения в активы стали менее эффективными. Рентабельность собственного капитала увеличивается и составляет 52,8\% на конец анализируемого периода. В экономической литературе указано, что нормальное значение данного показателя - не менее $16 \%$. Таким образом, отдача собственного капитала не высока. Маржа чистой прибыли составила 115,9 \% (таблица 5).

Показатели ликвидности дают общее представление о соотношении различных элементов текущих активов и пассивов. На конец 2016 года показатель текущей ликвидности, равный 1,66 свидетельствует о том, что на каждый тенге заимствованных средств приходится 1,66 тенге текущих активов компании и в случае острой необходимости организация с помощью текущих активов сможет погасить полностью текущие обязательства. За анализируемый период меньше рекомендуемого (2), но близок к нему. Значение коэффициента 
быстрой и абсолютной ликвидности снижается и ниже рекомендуемого значения. Анализ указывает на хорошее соотношение между собственным и заемным капиталом (32,7 \%). Анализ качества обслуживания долга по кредиту показал, что случаи просроченных платежей по процентам в течение последних 180 календарных дней отсутствуют. Источником денежных средств для возврата основного долга планируются средства, полученные по договорам.

Таблица 5. Финансовые коэффициенты АО «Фридом Финанс» за 2015-2016 гг.

\begin{tabular}{|c|c|c|c|}
\hline Показатели & 01.01 .2016 & 01.01 .2017 & Изменение \\
\hline \multicolumn{4}{|c|}{ Структура активов и пассивов } \\
\hline текущие активы/активы & $95,3 \%$ & 98,7 & 3,4 \\
\hline долгосрочные активы/ активы & $4,7 \%$ & 1,3 & $-3,4$ \\
\hline текущие обязательства/пассивы & $34,6 \%$ & 59,4 & 24,8 \\
\hline долгосрочные обязательства/пассивы & $0,3 \%$ & 7,9 & 7,6 \\
\hline капитал/пассивы & $65,0 \%$ & 32,7 & $-32,3$ \\
\hline \multicolumn{4}{|l|}{ Ликвидность } \\
\hline абсолютная ликвидность & 0,55 & 0,07 & $-0,5$ \\
\hline быстрая ликвидность & 0,58 & 0,10 & $-0,5$ \\
\hline текущая ликвидность & 2,75 & 1,66 & $-1,1$ \\
\hline \multicolumn{4}{|c|}{ Рентабельность } \\
\hline маржа чистой прибыли & $117,7 \%$ & 115,9 & $-1,8$ \\
\hline $\mathrm{ROA}$ & $19,8 \%$ & 17,3 & $-2,5$ \\
\hline ROE & $30,4 \%$ & 52,8 & 22,4 \\
\hline \multicolumn{4}{|c|}{ Кредитоспособность } \\
\hline активы/собственный капитал & 1,54 & 3,06 & 1,5 \\
\hline финансовый долг/собственный капитал & 0,00 & 0,00 & 0,0 \\
\hline Примечание - составлено по данным & тчет & Брид & i) [7] \\
\hline
\end{tabular}

Итак, показатели кредитоспособности АО «Фридом Финанс» хорошие. Кроме того, есть положительное подтверждение Рейтинговым агентством RAEX рейтинга кредитоспособности компании на уровне А «Высокий уровень кредитоспособности» (стабильный). На рост рейтинга оказало положительное влияние высокие показатели (по итогам 2016 г. ROA=26, \%, $\mathrm{ROE}=66 \%$ ), высокий уровень показателей и низкий уровень валютных рисков [9].

Кроме того, за счет того, что около $90 \%$ активов компании представляют собой акции, которые обращаются на фондовой бирже и в их стоимость уже включена сумма обесценивания, активы АО «Фридом Финанс» почти не подвержены обесценению. Кроме того, в компании выполняются пруденциальные нормативы по достаточности капитала, отмечен высокий уровень раскрытия финансовой информации и организации риск-менеджмента.

Выводы. В кризисных условиях экономической среды, изучение теоретических и практических основ анализа кредитоспособности и ее совершенствования служат той базой, на которой строится разработка и формирование стратегических, перспективных направлений развития компании.

К основным конкурентам компании относятся: AO «BCC Invest», AO «Halyk Finance», $\mathrm{AO}$ «Казкоммерц Секьюритиз», АО «Сентрас Секьюритиз». К негативным факторам, которые влияют на развитие компании, относятся слабое развитие отечественного фондового рынка. Можно отметить незначительную роль сектора корпоративных ценных бумаг рынка в экономике республики.

К проблемам фондового рынка относится низкая капитализация и недостаточное использование акций и облигаций в качестве механизма привлечения инвестиций в экономику предприятия. Хотя в 2017 году и наблюдается положительная динамика роста рынка ценных бумаг, но, тем не менее, его роль в экономике недостаточна. Доля сектора ценных бумаг в общем объеме торгов занимает около $2 \%$. На фондовом рынке наблюдается значительная доля институциональных инвесторов, покупающих ценные бумаги на длительный срок и осуществляющих взвешенную политику. Перспектива деятельности компании в секторе рынка ценных бумаг растет в связи с определёнными Главой государства Н.А. Назарбаевым задачами «перезагрузки» финансового сектора и открытием фондовой площадки в рамках МФЦА. Международный финансовый центр предполагает широкое использование новейших технологических решений, одно из них - применение блокчейн-технологии, использование крипто валюты 「10ๆ

По нашему мнению, будущее у крипто валюты в Казахстане есть, потому что она очень удобна с точки зрения диверсификации и снижения издержек. Приведем примеры применения блокчейн-технологий на фондовых рынках для эмитентов, и я инвесторов. В 2016 году 
компания Онлайн-ритейлер Overstock объявила о выпуске и размещении публичных акций (серии A-OSTKP) и Б-ОТСQВ), размещенных на платформе, полностью базирующихся на технологии блокчейн. В данных целях была разработана блокчейн-платформа $Ø$, которая мало отличается от традиционных биржевых платформ, кроме как наличием своей децентрализованной природы.

В октябре 2018 года российский Национальный расчётный депозитарий, в пилотном режиме провел размещение ценных бумаг с использованием технологии блокчейна на платформе Hyperledger Fabric. Прогрессивная технология использовалась для полного цикла жизни облигаций. В апреле 2017 Канадская биржа ценных бумаг объявила о запуске клиринговой блокчейн-платформы. $\mathrm{K}$ использованию блокчейн-технологий готов и Национальный банк Казахстана, проводится работка как на уровне МФЦА, так и на законодательном уровне в области поправок в закон «о валютном регулировании и валютном контроле», которые закрепят статус электронных денег, в том числе и крипто валюты.

Анализ проводимой маркетинговой стратегии показал, что компания принимает участие в инновационных проектах, как единственный андеррайтер провела казахстанское IPO среднего бизнеса и АО «Актюбинский завод металлоконструкций», осуществляет функции маркет-мейкера, является активным эмитентом и инвестором.

Конкурентный анализ показал, что компания является лидером среди конкурентов, имеет высокую деловую репутацию, эффективное корпоративное управление, отлаженную систему управления рисками. В команде компании собраны высококвалифицированные сотрудники, получающие достойную оплату труда и способные гибко реагировать на изменения как внешних, так и внутренних факторов. В результате деятельности на конец периода наблюдается рост чистой прибыли на $189,3 \%$, это связано с проведенными успешными сделками на фондовой бирже.

Организации финансового сектора в целом подвержены кредитному риску, возникающему в отношении финансовых активов и условных обязательств. Степень кредитного риска подвергается постоянному мониторингу с целью обеспечить соблюдение лимитов по кредитам и кредитоспособности в соответствии с утвержденной Компанией политикой по управлению рисками [7].

Показатели кредитоспособности АО «Фридом Финанс» находятся на высоком уровне. Подтверждение этому наличие положительного заключения Рейтинговым агентством RAEX по признанию рейтинга кредитоспособности компании на уровне А «Высокий уровень кредитоспособности» (стабильный). На рост рейтинга оказало положительное влияние высокая рентабельность (по итогам 2016 г. $\mathrm{ROA}=17,3 \%, \mathrm{ROE}=52,8 \%$ ), хорошие финансовые показатели. Кроме того, за счет того, что около $90 \%$ активов компании представляют собой акции, которые обращаются на фондовой бирже и в их стоимость уже включена сумма обесценивания, активы АО «Фридом Финанс» почти не подвержены обесценению.

\section{ЛИТЕРАТУРА}

1. Баканов М. И., Шеремет А. Д. «Финансовый анализ преприятия». М. : «Финансы и статистика», 2002 г.

2. Стоянов Е. С. «Финансовый менеджмент: теория и практика». М., «Перспектива», 2000

3. Жумаканов Ж. Т. Управление кредитными рисками банка в Казахстане //http://be5.biz/ekonomika1/r2012/2645.htm

4. Султанова А., Утегужина А. Организация управления кредитными рисками в банках второго уровня // Вестник КазНУ. - 2014. - № 1. - С. 102-106.

5. Джаксыбекова Г. Н., Нургалиева А. М. Банковский риск - менеджмент // Universum: Экономика и юриспруденция: электрон. научн. журн. 2015. № 3(14). URL: http://7universum.com/ru/economy/archive/item/1989 (дата обращения: 26.04.2018).

6. Деньги, кредит, банки: учебник / кол. авторов; под ред. Лаврушина О. И. - 9-е изд., стер. - М.: КНОРУС, 2013. - 441 с.

7. Годовой отчет АО «Фридом Финанс». hhttps://ffin.kz/about/fin-indicators (дата обращения: 11.03.2018).

8. Официальный интернет ресурс Национального Банка PK http://www.nationalbank.kz/ (дата обращения 04.03.2018)

9. Кредитоспособность компании АО «Фридом Финанс» на уровне А. https://ffin.kz/about/press-centr/ffin-kaz/ost-2-2 (дата обращения: 24.04.2018).

10. Международный финансовый центр Астана [Электронный ресурс] AIFChttp:// https://www.aifc.kz/ (дата обращения 17.03.2018 г.) 